\title{
Dorsal Radial Glial Cells Have the Potential to Generate Cortical Interneurons in Human But Not in Mouse Brain
}

\author{
Xiaojing Yu and Nada Zecevic \\ Department of Neuroscience, University of Connecticut Health Center, Farmington, Connecticut 06030
}

Radial glial (RG) cells, in the neocortical ventricular/subventricular zone (VZ/SVZ), generate cortical projection neurons both in rodents and humans, but whether they can also generate cortical interneurons is not clear. We demonstrated both on cryosections and in cell cultures that in the human VZ/SVZ, cells can be double labeled with RG markers and calretinin (CalR) and GABA, markers that suggest interneuronal lineage. We examined in more detail the cell fate of human RG cells isolated from the VZ/SVZ at midterm. After $24 \mathrm{~h}$, no $\mathrm{CalR}^{+}$or $\mathrm{GABA}^{+}$cells were seen in cultures, whereas $5-10 \%$ cells expressed Nkx2.1 and Dlx, two ventral transcription factors. CalR ${ }^{+}$and $\mathrm{GABA}^{+}$cells were apparent for the first time after $3 \mathrm{~d}$ in vitro, and their number increased in subsequent days, consistent with the gradual transition of RG cells into CalR ${ }^{+}$or $\mathrm{GABA}^{+}$cells. Indeed, the progeny of genetically labeled RG cells could be immunolabeled with antibodies to CalR and GABA or ventral transcription factors $\left(\mathrm{Nkx} 2 \cdot 1^{+}, \mathrm{Dlx}^{+}\right)$. In contrast to humans, in the embryonic mouse, similar experiments showed that only RG cells isolated from the subpallium (ganglionic eminence) generate CalR ${ }^{+}$or GABA $^{+}$cells, whereas this was not the case with RG cells isolated from the pallium. These findings support the idea that human, but not mouse, dorsal RG cells have the potential to generate various subtypes of neocortical interneurons. Multiple progenitors and sites of cortical interneuron origin in human might be an evolutionary adaptation underlying brain expansion and the increased complexity of cortical circuitry in humans.

\section{Introduction}

The complex function of the cerebral cortex critically depends on the balanced development of cortical circuitry between excitatory projection neurons and inhibitory interneurons. The human cerebral cortex develops over a long time period from a variety of progenitor cells that are dividing first in the ventricular zone (VZ) and subsequently in the subventricular zone (SVZ) (Rakic and Zecevic, 2003b; Howard et al., 2006, 2008; Bayatti et al., 2008; Bystron et al., 2008). Recent observations based on immunolabeling of fetal human and monkey brains have suggested that in addition to cortical interneurons derived from the ganglionic eminence (GE), a substantial percentage may arise from the neocortical VZ/SVZ (Letinic et al., 2002; Rakic and Zecevic, 2003b; Zecevic et al., 2005, 2011; Fertuzinhos et al., 2009; Petanjek et al., 2009a,b).

In human development, in the early embryonic and fetal stages [6-15 gestational weeks (g.w.)], the GE is the main source of neocortical interneurons, whereas at midterm (20 g.w.), these cells are also generated from distinct progenitors in the outer neocortical SVZ (oSVZ). The oSVZ, as an additional proliferative zone, is typical for species with gyrencephalic brains and is particularly well developed in primates (Smart et al., 2002; Zecevic et

Received Oct. 6, 2010; revised Dec. 2, 2010; accepted Dec. 10, 2010.

This work was supported by National Institutes of Health Grant NS41489/10 and Connecticut Innovation Stem Cell Grant 2008-013. We thank Dr. Igor Jakovcevski for critical review of this manuscript, Nicole Mayer for helping with immunostaining, and Dr. B. Poulos (The Tissue Repository, Albert Einstein College of Medicine, Bronx, NY) for providing autopsy specimens of human fetal brain tissue.

Correspondence should be addressed to Nada Zecevic, Department of Neuroscience, University of Connecticut Health Center, 263 Farmington Avenue, Farmington, CT 06030. E-mail: nzecevic@neuron.uchc.edu.

DOI:10.1523/JNEUROSCI.5249-10.2011

Copyright $\odot 2011$ the authors $\quad 0270-6474 / 11 / 312413-08 \$ 15.00 / 0$ al., 2005; Fietz et al., 2010; Hansen et al., 2010). We reported that radial glial (RG) cells, multipotent progenitors abundant in the human SVZ at midterm (Howard et al., 2006), generate all main neural cell types: astrocytes, projection neurons, and oligodendrocytes (Mo et al., 2007; Mo and Zecevic, 2008, 2009). We also demonstrated that cells isolated from the midterm human neocortical SVZ also have the potential to generate calretininpositive $\left(\mathrm{CalR}^{+}\right)$cells (Mo et al., 2007). Moreover, at the same gestational age (midterm, 20 g.w.), a small number of CalR ${ }^{+}$cells have been seen to proliferate in the human VZ/SVZ (Jakovcevski et al., 2010; Zecevic et al., 2011), consistent with their local origin. The idea that a CalR ${ }^{+}$population is generated in the neocortical SVZ is strengthened by their sparing in the cortex of patients with severe holoprosencephaly, where the GE is essentially absent (Fertuzinhos et al., 2009). We now report that combined results of double immunolabeling of human fetal brain cryosections, as well as cell-fate mapping with the Cre-LoxP method in vitro, demonstrate that progeny of RG cells can be labeled with markers of cortical interneurons and ventral transcription factors. Together, these results suggest that dorsal RG cells can generate neocortical interneurons. In contrast, similar experiments in the embryonic day 16 (E16) to E17 mice demonstrate that only RG cells from the subpallium (ventral telencephalon) and not from the pallium (dorsal telencephalon) have a potential to generate cortical interneurons, in agreement with previous reports on the ventral origin of cortical interneurons in rodents (de Carlos et al., 1996; Anderson et al., 1997, 1999; Tamamaki et al., 1997; Lavdas et al., 1999; Marin and Rubenstein, 2001). Hence, these results support the direct lineage relationship between dorsal RG cells and neocortical interneurons in human brain, but not in the mouse brain. 


\section{Materials and Methods}

Human fetal brain tissue and cell culture. Human fetal brain tissue $(n=4)$, ranging in age from 19 to 21 g.w. (corresponding to postconceptional weeks, full term being 40 g.w.), was collected from the Human Fetal Tissue Repository at the Albert Einstein College of Medicine (Bronx, NY), after legal abortions and with proper consent from parents. The postmortem delay was, on average, $15 \mathrm{~min}$. The tissue was handled with care, following all necessary regulations set by the Ethics Committee of the University of Connecticut and the Helsinki Declaration. In all studied cases, ultrasound and gross neuropathological examination excluded brain pathology. Brain tissue was collected in oxygenized HBSS (Invitrogen) and transported on ice to our laboratory $(1.5 \mathrm{~h}$ drive) where it was dissected into blocks for frozen sections (see below) and cell cultures. Dissociated cell cultures were prepared from the cortical VZ/SVZ of the fetal forebrain as described previously (Zecevic et al., 2005). The tissue was dissociated with $0.05 \%$ trypsin $/ 0.02 \%$ EDTA (Invitrogen) and triturated through a firepolished pipette. Cells were resuspended in DMEM/F-12 (Invitrogen) containing $10 \mathrm{ng} / \mathrm{ml}$ basic fibroblast growth factor (bFGF; Peprotech) or $10 \mathrm{ng} / \mathrm{ml}$ epidermal growth factor (EGF; Millipore) supplemented with B27 (Invitrogen) and N2 (Invitrogen), seeded onto poly-L-lysine (Sigma)-coated four-well plates at a concentration of $1 \times 10^{5}$ cells per well. Acute cell cultures were incubated at $37^{\circ} \mathrm{C}$ with $5 \% \mathrm{CO}_{2}$ and $95 \% \mathrm{O}_{2}$ for $4 \mathrm{~h}$, fixed in $4 \%$ paraformaldehyde for $15 \mathrm{~min}$, and processed for immunostaining.

Immunopanning and cell cultures. We used immunopanning with the cell-surface marker LeX (fucose $N$-acetyl lactosamine), an extracellular matrix-associated carbohydrate, also known as SSEA1 or CD15, to enrich human RG cells according to a procedure described previously (Mo et al., 2007). In short, $100 \mathrm{~mm}$ tissue culture dishes were precoated with a secondary antibody (goat anti-mouse IgM; SouthernBiotech) overnight at $4^{\circ} \mathrm{C}$. The next day, the dishes were rinsed with PBS, incubated with $5 \mathrm{ml}$ of anti-LeX antibody (1:100; Lab Vision) in PBS with $0.2 \%$ BSA at room temperature for $2 \mathrm{~h}$, followed by another PBS wash. The dissociated cells $\left(10^{7}\right)$ suspended in $10 \mathrm{ml}$ of DMEM/F-12 (Invitrogen) supplemented with $10 \mathrm{ng} / \mathrm{ml}$ bFGF or $10 \mathrm{ng} / \mathrm{ml}$ EGF were incubated on the anti-LeX-coated dishes for $20 \mathrm{~min}$ at room temperature with gentle agitation. Thereafter, the nonadherent cells were removed by rinsing, whereas adhered $\mathrm{LeX}^{+}$cells were detached from the dish with trypsin-EDTA (Invitrogen), counted, and plated on $12 \mathrm{~mm}$ precoated poly-L-lysine coverslips (Carolina Biological Supply). Initially, $\mathrm{LeX}^{+}$cells represented $95 \%$ of the immunopanned cells. The cells were cultured in the proliferation medium (PM) (DMEM/F-12/ $\mathrm{B} 27 / \mathrm{N} 2,10 \mathrm{ng} / \mathrm{ml} \mathrm{bFGF}$, or $10 \mathrm{ng} / \mathrm{ml}$ EGF) up to $5 \mathrm{~d}$. Subsequently, cells were transferred to a differentiation medium (DM) (DMEM/F-12/B27/ $\mathrm{N} 2$, without bFGF and EGF) and kept for another $7 \mathrm{~d}$ in culture. Total culturing time was then 12 days in vitro (div) (see Fig. 1).

Plasmids and LeX ${ }^{+}$cell transfection. To selectively label RG cells and trace their progeny, we cotransfected RG cells with brain lipid-binding protein (BLBP)-Cre and Floxed yellow fluorescent protein (YFP) plasmids, as described previously (Mo et al., 2007). LeX ${ }^{+}$cells were cultured onto $12 \mathrm{~mm}$ coverslips in the expansion medium for 1 div and transfected or cotransfected with plasmids using Lipofectamine 2000 (Invitrogen) according to the manufacturer's protocol. Scale bars, $\mathbf{A}-\mathbf{0}, 20 \mu \mathrm{m}$.
Table 1. Proportion of cells that express a specific marker in mixed cell culture isolated from the human cortical VZ/SVZ region

\begin{tabular}{llll}
\hline Marker & $4 \mathrm{~h}$ & $5 \operatorname{div}(\mathrm{PM})$ & $7 \operatorname{div}(\mathrm{DM})$ \\
\hline Nkx2.1 & $24.6 \pm 0.9 \%$ & $35.8 \pm 0.48 \%$ & $47.4 \pm 0.57 \%$ \\
Dlx & $38.4 \pm 1.4 \%$ & $45.8 \pm 1.6 \%$ & $53.4 \pm 1.8 \%$ \\
CalR & $15.7 \pm 0.3 \%$ & $20.4 \pm 1.3 \%$ & $22.1 \pm 1.4 \%$ \\
GABA & $17.7 \pm 0.6 \%$ & $12.3 \pm 0.5 \%$ & $16.2 \pm 0.6 \%$ \\
\hline
\end{tabular}
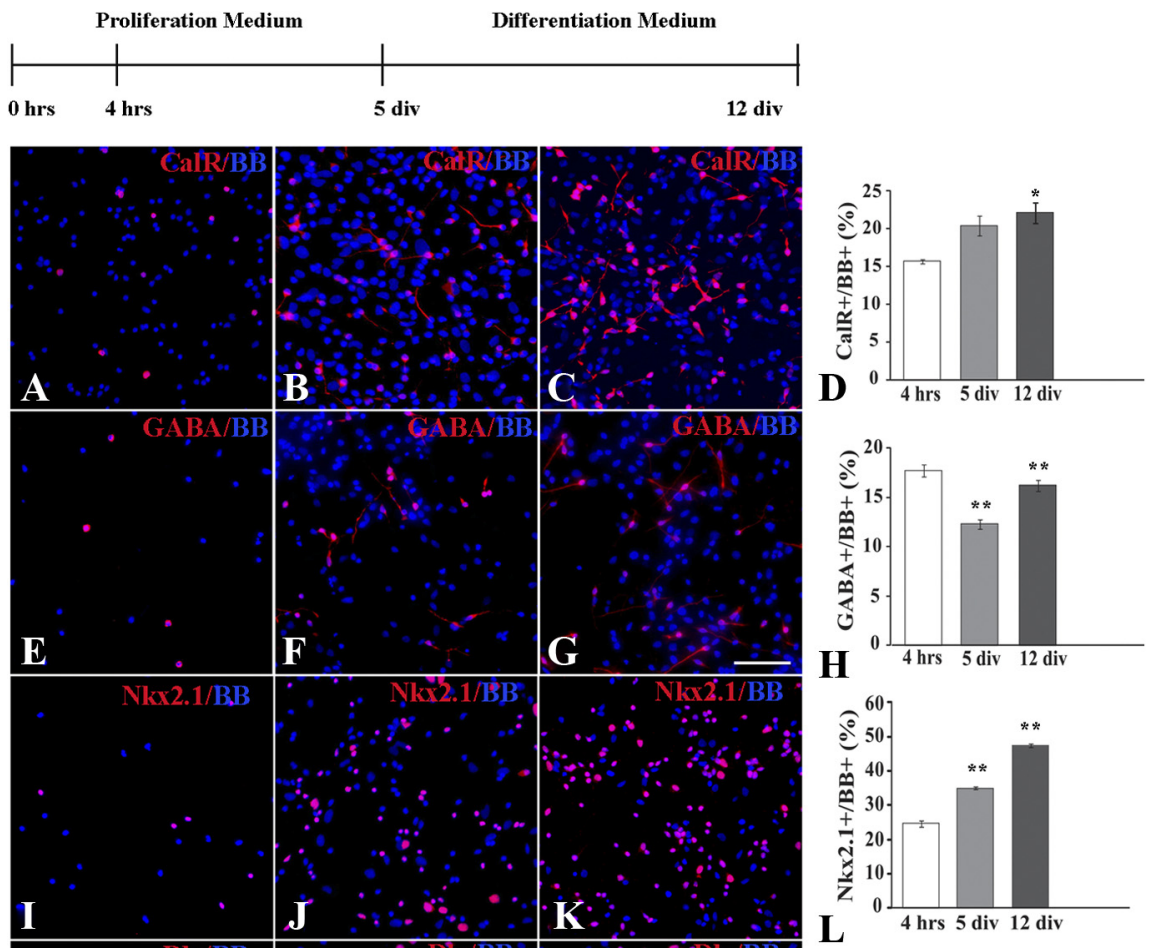
show corresponding percentages over time $(\boldsymbol{D}, \boldsymbol{H}, \boldsymbol{L}, \boldsymbol{P})$. Blue-nuclear bisbenzamide staining was used. ${ }^{*} p \leq 0.05 ;{ }^{* *} p \leq 0.001$.

Immunostaining of cryosections and cell cultures. Human fetal tissue was dissected into frontally cut blocks (for details, see Jakovcevski and Zecevic, 2005), fixed overnight in $4 \%$ formaldehyde solution in $0.1 \mathrm{M}$ phosphate buffer, cryoprotected by $30 \%$ sucrose, frozen in isopentane, cooled to $-70^{\circ} \mathrm{C}$, and cut into $15 \mu \mathrm{m}$ coronal sections for immunohistochemistry. Next, antigen unmasking was done by immersing sections in $0.01 \mathrm{M} \mathrm{Na}$-citrate solution, $\mathrm{pH} \mathrm{9,} \mathrm{for} 20 \mathrm{~min}$ at $60-80^{\circ} \mathrm{C}$. Cultures of human fetal brain cells were fixed in $4 \%$ paraformaldehyde for $15 \mathrm{~min}$. The following antibodies were applied overnight to the cryosections and cultures diluted in the blocking solution ( $1 \%$ BSA, $5 \%$ normal goat serum, and $0.5 \%$ Tween 20 in PBS): anti-BLBP (1:2000; gift from $\mathrm{N}$. Heintz, The Rockefeller University, New York, NY), anti-vimentin (1: 200; Sigma), anti-GFAP (1:2000; Dako), anti-CalR (1:500; Millipore), anti-Nkx2.1 (1:2000; Epitomics), pan anti-Dlx (1:2000, antibody Dll; a gift from Dr. Y. Morozov, Yale University, New Haven, CT; labels Dlx isoforms 1, 2, 5, and 6), anti-GABA (1:3000; Sigma), and a mixture of 



Figure 2. Human and mouse cryosections and cultures. $\boldsymbol{A}-\boldsymbol{C}$, Immunofluorescence of cryosections at 20 g.w. fetal brain vimentin (Vim; red) and Nkx2.1 (green) in the cortical VZ/SVZ. Inset, Higher magnification of colabeled cell. $\boldsymbol{D}$, In the coronal section of the E16 mouse forebrain, there is a strong Nkx2.1 expression (green) in the subpallium but not in the pallium. LGE, Llateral GE; LV lateral ventricle; Sep, septal area; Str, striatum. $\boldsymbol{E}, \boldsymbol{F}$, Higher magnification of the cortex $(\boldsymbol{E})$ and $M G E(\boldsymbol{F})$. $\boldsymbol{G}$, In acute cell culture (4 h), cells isolated from the human cortical VZ/SVZ at midterm express Nkx2.1 (red). $\boldsymbol{H}, \boldsymbol{I}$, In contrast, in E16 mouse cell culture from the pallium $(\boldsymbol{H}), \mathrm{Nkx2.1}$ is not demonstrated, but there are numerous $\mathrm{Nkx2.1^{+ }}$ cells in the subpallium culture $(\boldsymbol{I}$, green and arrows). The dashed line in $\boldsymbol{A}-\mathbf{C}$ represents the ventricular surface. $B B$, Blue bizbenzamide nuclear stain. Scale bars: $\mathbf{A}-\mathbf{C}, \mathbf{G}-\mathbf{I}, 20$ $\mu \mathrm{m}$; inset, $10 \mu \mathrm{m} ; \mathbf{D}-\boldsymbol{F}, 50 \mu \mathrm{m}$.

vGlut 1 and vGlut2 (1:1, vesicular glutamate transporter; 1:1000; Synaptic Systems). Primary antibodies were applied overnight at $4^{\circ} \mathrm{C}$, followed by corresponding secondary antibodies (Jackson ImmunoResearch Laboratories) for $1 \mathrm{~h}$ and a short incubation in the nuclear stain bisbenzamide (Sigma). Cell apoptosis was tested with immunoreactions to caspase3 antibody and the TUNEL (terminal deoxynucleotidyl transferasemediated biotinylated UTP nick end labeling) method as described previously (Mo and Zecevic, 2008). Coverslips were viewed with the Axioskop microscope (Zeiss).

Cell counting and statistical analysis. Cells stained with the nuclear stain bisbenzamide and various cellular markers were visualized with a Zeiss fluorescence microscope and photographed with a digital camera. Before quantification, 10 predesignated, adjacent optical fields of view were selected in each culture and examined at magnification $20 \times$ (one field has a surface area of $0.5 \mathrm{~mm}^{2}$ ). The percentage of immunolabeled cells of total bisbenzamide or YFP- or green fluorescent protein-positive cells was calculated. The data were expressed as means \pm SEMs and analyzed using Student's $t$ tests. The criterion for significance was set at $p \leq 0.05$.

Mouse brains. Timed pregnant CD1 mice (E16-E17, $n=10$; Charles River Laboratories) were used in this study. The pallium (dorsal telencephalon, containing cortical anlagen) and the subpallium (ventral telencephalon, containing the GE) were dissected from the forebrain and cultured separately. The same methods and experiments as described for human tissue were used. All experiments were done in triplicate.

Technical note. Although both calretinin and GABA can be expressed in other cell types, such as rare pyramidal cells for calretinin and projec- tion neurons of basal ganglia for GABA, they are widely accepted as markers of cortical interneurons (DeFelipe 2002). Here we refer to cells expressing these proteins as belonging to the interneuronal lineage (see supplemental Fig. 1, available at www.jneurosci.org as supplemental material).

\section{Results}

Interneuronal progenitors in the human fetal VZ/SVZ cultures

We isolated and cultured cells from cortical VZ/SVZ of 19-22 g.w. human fetal brains $(n=4)$. Initially, in acute cell cultures (after $4 \mathrm{~h}$ ), about one-third and one-quarter of cells expressed ventral transcription factors Dlx and Nkx2.1, respectively (Table 1, Fig. 1). Two interneuronal markers, CalR and GABA, labeled fewer cells, between 15 and $17 \%$ of all cells in acute cultures (Table 1). After $5 \mathrm{~d}$ ( $5 \mathrm{div}$ ) in the PM (with $10 \mathrm{ng} / \mathrm{ml}$ bFGF), the percentages of $\mathrm{Nkx} 2.1^{+}, \mathrm{Dlx}{ }^{+}$, and $\mathrm{CalR}^{+}$cells increased substantially, suggesting their proliferation. An increase in the number of CalR ${ }^{+}$cells is in agreement with our finding of proliferating CalR ${ }^{+}$cells in neocortical VZ/SVZ on cryosections at 20 g.w. (Yu et al., 2009; Jakovcevski et al., 2010; Zecevic et al., 2011).

The number of GABA ${ }^{+}$cells in our cultures, however, decreased by $30 \%$ during the same period, suggesting that GABA cells do not have the ability to proliferate, which resulted in a reduction of their number relative to other cells (Table 1, Fig. 1). These results, obtained in dispersed cell cultures, are consistent with the previous results in human fetal brain slice cultures, in which a fraction of cells that expressed Nkx2.1 and Dlx were proliferating, as seen by their colabeling with bromodeoxyuridine, whereas none of the $\mathrm{GABA}^{+}$cells incorporated this proliferation marker (Zecevic et al., 2005). After an additional 7 div in differentiation medium (without bFGF), the percentages of cells labeled with Nkx2.1, Dlx, CalR, and GABA antibodies increased (Fig. 1). The highest increase was demonstrated for $\mathrm{Nkx}_{2} .1^{+}$and $\mathrm{GABA}^{+}$cells $(32 \%)$, whereas Dlx ${ }^{+}$and $\mathrm{CalR}^{+}$cells increased 17 and $8.3 \%$, respectively (Table 1, Fig. 1). This finding indicates that the initially isolated progenitors differentiate and start expressing these markers, in agreement with the idea that human dorsal progenitor cells have the potential to generate interneuron lineage in vitro.

However, a variety of progenitors is present in the dorsal cortical VZ/SVZ, and especially in the enlarged outer SVZ of the human fetal brain at midterm (Zecevic et al., 2005; Bayatti et al., 2008; Fietz et al., 2010; Hansen et al., 2010; Zecevic et al., 2011). Thus, we next asked which progenitor subtype is the most likely to generate neocortical interneurons.

\section{Enriched RG cells generate interneurons in vitro}

On cryosections of human fetal forebrain at midterm (20 g.w.), we established that a fraction of cells coexpresses the RG marker vimentin and a ventral transcription factor, Nkx2.1 (Fig. 2A-C). Their percentage was small, around $2 \%$ of all cells in the cortical VZ/SVZ, but it is in sharp contrast to results obtained in the E16 



$\square \mathrm{Nkx} 2.1+$

$\square$ Dlx +

घ $\mathrm{Nkx2.1+Vim+}$

alx + Vim +

$\square$ CalR+

口CalR+BLBP+

$\square \mathrm{GABA}^{+}$ GABA+Vim+


Figure 3. Human Lex ${ }^{+}$cells coexpress markers for radial glia and interneurons in the same cells in vitro. $A-D$, After $24 \mathrm{~h}$ in the proliferation medium, the majority of LeX ${ }^{+}$cells are colabeled with one of the RG markers: Pax6 $(\boldsymbol{A})$, vimentin $(\operatorname{Vim} ; \boldsymbol{B}), \operatorname{GFAP}(\boldsymbol{C})$, or BLBP $(\boldsymbol{D})$. $\boldsymbol{E}-\boldsymbol{H}$, After 3 div, representative images of cells double labeled with Nkx2.1 and Vim $(\boldsymbol{E})$, DIx and Vim $(\boldsymbol{F})$, CalR and BLBP $(G)$, and GABA and $\operatorname{Vim}(\boldsymbol{H})$ are shown. $\boldsymbol{I}-\boldsymbol{L}$, Graphs demonstrate the proportion of single- and double-labeled cells from all the cells in the above illustrated cultures after $24 \mathrm{~h}$ in PM and after 3 and 7 div in DM. Scale bars, $\boldsymbol{A}-\boldsymbol{H}, 20 \mu \mathrm{m} .{ }^{*} p<0.05 ;{ }^{* *} p<0.001$.

Table 2. Proportion of cells that express a specific marker in enriched RG cells from the human cortical VZ/SVZ region

\begin{tabular}{|c|c|c|c|}
\hline Marker & $24 \mathrm{~h}$ & $3 \operatorname{div}(\mathrm{DM})$ & $7 \operatorname{div}(\mathrm{DM})$ \\
\hline Nkx2.1 & $10.2 \pm 0.9 \%$ & $20 \pm 1 \%$ & $22 \pm 1.2 \%$ \\
\hline $\mathrm{Nkx} .1^{+} /$vimentin ${ }^{+}$ & $9.9 \pm 0.8 \%$ & $17 \pm 2 \%$ & $8.1 \pm 1.3 \%$ \\
\hline Dlx & $4.5 \pm 1.7 \%$ & $15 \pm 1.9 \%$ & $20 \pm 2 \%$ \\
\hline $\mathrm{Dlx}^{+} /$vimentin ${ }^{+}$ & $4 \pm 0.8 \%$ & $5.2 \pm 0.6 \%$ & $2.6 \pm 0.9 \%$ \\
\hline CalR & $0 \pm 0 \%$ & $10.5 \pm 0.7 \%$ & $15 \pm 0.6 \%$ \\
\hline $\mathrm{CalR}^{+} / \mathrm{BLBP}^{+}$ & $0 \pm 0 \%$ & $3.1 \pm 0.3 \%$ & $0.7 \pm 0.2 \%$ \\
\hline GABA & $0 \pm 0 \%$ & $9.8 \pm 0.6 \%$ & $15.8 \pm 0.5 \%$ \\
\hline $\mathrm{GABA}^{+} /$vimentin $^{+}$ & $0 \pm 0 \%$ & $2.8 \pm 0.6 \%$ & $0.6 \pm 0.2 \%$ \\
\hline
\end{tabular}

mouse brain, where Nkx2.1 is not expressed at all in the dorsal telencephalon (Fig. $2 D, E$ ). These results were confirmed in vitro, where Nkx2.1 transcription factors were expressed in cells from human cortical VZ/SVZ and mouse subpallium but not in cultures from the mouse pallium (Fig. $2 G-I$ ). To study the potential of human RG cells to generate cortical interneurons more directly, we enriched RG cells from the neocortical VZ/SVZ of 19-22 g.w. human fetal brains $(n=4)$ using the previously described immunopanning method (Mo et al., 2007). After $24 \mathrm{~h}$, the majority (95\%) of the immunopanned cells were labeled with RG markers, including vimentin, BLBP, Pax6, and GFAP (Fig.
$3 A-D)$. Furthermore, among all cells in culture, $9.9 \pm 0.8 \%$ were colabeled with both $\mathrm{Nkx} 2.1$ and vimentin, and $4 \pm 0.8 \%$ coexpressed Dlx and vimentin (Fig. 3, Table 2). However, CalR or GABA antibodies, accepted markers of cortical interneurons, did not appear in the RG cell culture at this time point (Table 2). Therefore, initially in our cultures, the main progenitor cells were RG cells. Next, we transferred cultures to DM (without bFGF), which changed the cell phenotype in a time-dependent manner. After 3 div, the percentage of $\mathrm{Nkx} 2.1^{+}$cells from all cells in these cultures doubled, whereas the percentage of $\mathrm{Dlx}^{+}$increased threefold (Table 2, Fig. 3). Furthermore, the percentage of $\mathrm{Nkx} 2.1^{+} /$vimentin ${ }^{+}$cells increased by over $70 \%$, suggesting that with time more vimentin ${ }^{+}$RG cells start expressing Nkx2.1 transcription factor (Table 2, Fig. 3). Notably, after 3 div, we observed for the first time in these cultures CalR ${ }^{+}$and $\mathrm{GABA}^{+}$cells that each accounted for $\sim 10 \%$ of cells (Table 2, Fig. $3 G, H$ ). The proportion of $\mathrm{GABA}^{+} / \mathrm{vi}-$ mentin ${ }^{+}$double-labeled cells was around $3 \%$. This was similar to the percentage of $\mathrm{CalR}^{+} / \mathrm{BLBP}^{+}$cells where we used a different interneuron (CalR) and RG marker (BLBP) (Table 2, Fig. 3). This relatively small percentage is probably caused by downregulation of RG markers in the course of their differentiation into interneurons. 



Figure 4. A fraction of BLBP-Cre LoxP-transfected human RG cells generate cells of the interneuron lineage after 7 div differentiation: $\boldsymbol{A}-\boldsymbol{C}$, CalR (red, arrow); $\boldsymbol{D}-\boldsymbol{F}, \mathrm{GABA}$ (red, arrow); G-I, Nkx2.1 ${ }^{+}$(red, arrow); J-L, Dlx ${ }^{+}$(red, arrow) cells. Scale bar: (in $\boldsymbol{L}) \boldsymbol{A}-\boldsymbol{L}, 20 \mu \mathrm{m}$. The top diagram shows the time scale for particular in vitro experiments with proliferation $(10 \mathrm{ng} / \mathrm{ml} \mathrm{bFGF})$ and differentiation (without bFGF) medium.

Both the presence of these double-labeled cells and cells single labeled for CalR or GABA after 3 div suggest differentiation of human RG cells into cortical interneurons in our cultures. This is supported by the finding that between 3 and 7 div, the percentage of single-labeled CalR ${ }^{+}$and $\mathrm{GABA}^{+}$cells further increased by 43 and $61 \%$, respectively (Table 2, Fig. 3 ). On the other hand, the number of single-labeled Nkx2.1 ${ }^{+}$cells changed very little, whereas the number of $\mathrm{Nkx} 2.1^{+} /$vimentin ${ }^{+}$cells actually decreased by $52 \%$ (Table 2, Fig. 3) in the same time frame. The decrease of these double-labeled progenitors from 3 to 7 div is in contrast to the sharp increase seen in the first 3 div of differentiation, arguing for progressive differentiation of these progenitors into $\mathrm{CalR}^{+}$and $\mathrm{GABA}^{+}$ interneurons. In addition, the capacity of RG cells to express Nkx2.1 might decrease over time in cell culture. To verify that CalR is a marker of cortical interneurons and not pyramidal cells, we double labeled our cultures with a mixture of vGlut1 and vGlut2, markers of glutamatergic pyramidal cells, and CalR. Double-labeled CalR/vGlut cells were not observed, which substantiated that CalR is a valid marker of cortical interneurons in our experiments (supplemental Fig. 1, available at www.jneurosci.org as supplemental material).

Progeny of genetically labeled RG cells To confirm the results obtained by double immunolabeling of cryosections and enriched RG cell cultures, we genetically labeled RG cells in vitro to be positive that we are specifically following their progeny. We cotransfected enriched RG cultures with the plasmids BLBP-Cre and Floxed-YFP under a $\beta$-actin-based promoter. Using this method, only cells expressing BLBP that contain Cre could remove the stop signal preceding YFP and express YFP fluorescence. The YFP signal (green) remains in the cells even after the BLBP expression is downregulated in a process of cell differentiation.

The specificity of BLBP-Cre and FloxedYFP cotransfection was confirmed by double-labeling experiments with Cre and BLBP antibodies $1 \mathrm{~d}$ after cotransfection. The Cre activity, directed to RG cells by the BLBP promoter, has been shown only in $\mathrm{BLBP}^{+}$cells (supplemental Fig. 2A-C, available at www.jneurosci.org as supplemental material). Moreover, the YFP signal was only shown in $\mathrm{Cre}^{+}$cells (supplemental Fig. $2 D-F$, available at www.jneurosci.org as supplemental material), and all $\mathrm{YFP}^{+}$cells were also $\mathrm{BLBP}^{+}$(supplemental Fig. 2G-I, available at www.jneurosci.org as supplemental material). Thus, the YFP signal is specific for BLBP-expressing RG cells. Transfected cells were not selectively dying (supplemental Fig. 5, available at www. jneurosci.org as supplemental material). After $7 \mathrm{~d}$ of differentiation, a fraction of $\mathrm{YFP}^{+}$ transfected RG cells were colabeled with interneuronal markers CalR $(5 \pm 0.6 \%)$ and GABA $(8 \pm 0.7 \%)$ and with transcription factors $\mathrm{Nkx} 2.1(8.6 \pm 0.4 \%)$ and Dlx $(9.6 \pm$ $0.6 \%$ ) (Fig. 4). Therefore, the cell-fate tracing experiment in vitro confirmed that a subset of human cortical RG cells generate cells of interneuronal lineage labeled with CalR and GABA antibodies.

\section{The effect of growth factors on differentiation of interneurons in vitro}

Our previous data showed that high doses of bFGF in the medium have a proliferative effect on $\mathrm{Lex}^{+} \mathrm{RG}$ cells but did not change their identity up to 7 div in culture (Mo et al., 2007). Other studies, how- 
ever, suggested that adding bFGF in vitro favors generation of interneurons (Pappas and Parnavelas, 1998).

We did the same fate-mapping experiment by adding another growth factor, the EGF, instead of bFGF in the proliferation medium. Similar results were obtained with both growth factors (compare Fig. 4 and supplemental Fig. 3, available at www.jneurosci.org as supplemental material). After 7 div in differentiation medium, $8 \pm 0.4 \%$ of transfected RG cells differentiated into $\mathrm{Nkx} 2.1^{+}, 10 \pm 0.8 \%$ differentiated into $\mathrm{Dlx}^{+}, 4.2 \pm 0.7 \%$ differentiated into $\mathrm{CalR}^{+}$, and $8.5 \pm 0.7 \%$ differentiated into $\mathrm{GABA}^{+}$cells (supplemental Fig. 3, available at www.jneurosci.org as supplemental material). These results demonstrate that bFGF does not have any specific effect on cell-fate determination of RG cells in vitro.

\section{Mouse E16 brain}

To investigate whether our in vitro results are species specific, we studied the E16-E17 mouse brain. Cells isolated from the subpallium, which consists mainly of the GE, and the pallium (dorsal telencephalon) was maintained under the same in vitro conditions as the human fetal brain cell. Immunostaining with antibodies to Nkx2.1, Dlx, CalR, and GABA was done at $4 \mathrm{~h}, 5 \mathrm{div}$ in proliferation medium (with $10 \mathrm{ng} / \mathrm{ml}$ bFGF) and another 7 div in differentiation medium (without bFGF; time line shown in Fig. 1). At any time point, $\mathrm{Nkx} 2 \cdot 1^{+}$cells were found only in the mouse cultures from the subpallium and not the ones from the pallium (Fig. 2G-I, supplemental Table 1, available at www.jneurosci.org as supplemental material). Dlx, CalR, and GABA were expressed both in the subpallium and pallium cultures, similar to results in human cultures (supplemental Table 1, available at www.jneurosci.org as supplemental material).

Subsequently, we genetically labeled enriched mouse RG cells with the same BLBP-Cre LoxP method as used in human tissue. After 7 div of differentiation, only RG from the subpallium generated cells that were colabeled with CalR or GABA (Fig. 5) and ventral transcription factors Nkx2.1 and Dlx (supplemental Fig. 4). In contrast, the progeny of RG cells from the pallium did not generate cells colabeled with interneuron markers CalR and GABA (Fig. 5).

\section{Discussion}

Two potentially important results related to human cortical interneurons were obtained in this study. First, progenitor cells from human SVZ at midterm generated cells that were labeled with interneuron markers, CalR and GABA, or with two ventral transcription factors, Nkx2.1 and Dlx. These transcription factors are important for specification of cortical interneurons (Anderson et al., 1997, 1999; Sussel et al., 1999; Xu et al., 2005) but also have a role in oligodendrocyte specification (He et al., 2001; Marshall and Goldman, 2002; Rakic and Zecevic, 2003a,b; Kessaris et al., 2006).
Differentiation Medium

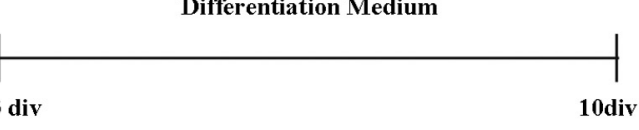

Pallium

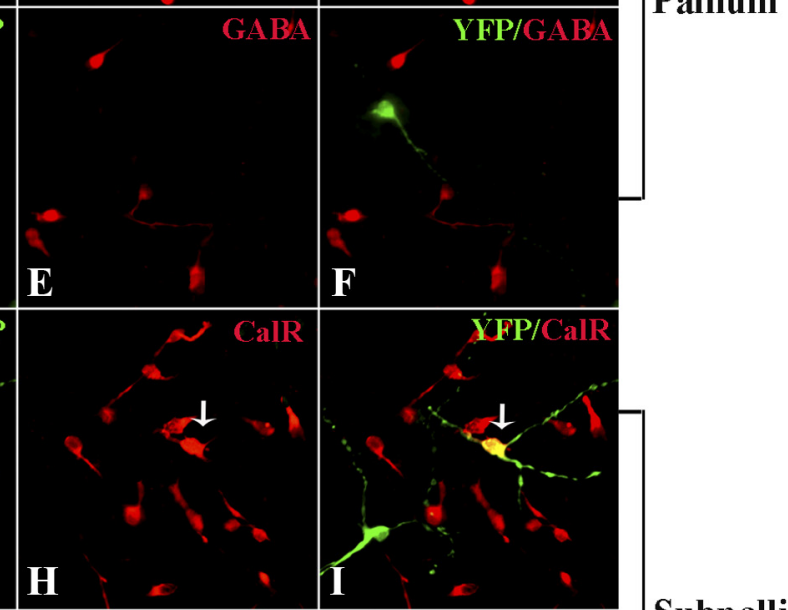

Subpallium



Figure 5. Mouse RG cells isolated from the forebrain at E16, transfected with BLBP-Cre LoxP and differentiated for 7 div. $\boldsymbol{A}-\boldsymbol{F}$, $R G$ from the pallium (dorsal telencephalon) do not generate cells labeled with either $C a I R(A-C$, red) or GABA ( $D-F$, red). $G-L$, In contrast, $R G$ cells from the subpallium (ventral telencephalon) generate cells in the interneuron lineage, $\mathrm{CalR}^{+}(\mathbf{G}-\mathbf{I}$, red, arrow) and $\mathrm{GABA}^{+}(\boldsymbol{J} \boldsymbol{L}$, red, arrow) cells. Scale bar: (in $\boldsymbol{L}) \boldsymbol{A}-\boldsymbol{L}, 20 \mu \mathrm{m}$. The top diagram shows the time scale for particular in vitro experiments with proliferation ( $10 \mathrm{ng} / \mathrm{ml} \mathrm{bFGF)} \mathrm{and} \mathrm{differentiation} \mathrm{(without} \mathrm{bFGF)} \mathrm{medium.}$

Second, we specifically identified RG cells as one of the SVZ progenitors that generate this subset of neocortical interneurons. Fate mapping with the Cre/loxP method allowed us to conclude that RG cells are one of the progenitors that generate late neocortical interneurons in the human fetal SVZ. Our estimate is that between 5 and $10 \%$ of transfected RG cells generate cortical interneurons in vitro, but the real number is difficult to calculate because of low (10\%) transfection efficacy in our experiments.

These in vitro results corroborate the role of human dorsal RG as progenitors of not only projection neurons, astrocytes, and oligodendrocytes (Mo et al., 2007; Mo and Zecevic, 2009) but also of cortical interneurons.

\section{Human versus rodent cortical interneurons}

Our knowledge of the origin and development of cortical interneurons was almost exclusively based on the studies from rodents, where they arise predominantly from the medial ganglionic eminence (MGE) and caudal ganglionic eminence (CGE) and migrate tangentially to the dorsal telencephalon (de Carlos et al., 1996; Anderson et al., 1997, 1999; Tamamaki et al., 1997; 
Lavdas et al., 1999; Marin and Rubenstein, 2001; Kanatani et al., 2008; Miyoshi et al., 2010).

Recently, a population of dorsally generated mainly CalR ${ }^{+}$ cells in rodents was reported to be destined for the olfactory bulb (Kohwi et al., 2007) and even dispersed throughout the cortex (Inta et al., 2008). Moreover, in vitro studies showed that dorsal progenitors could be differentiated into GABAergic cells (Gotz and Bolz, 1994; He et al., 2001; Gulacsi and Lillien, 2003). Thus, it is possible that a small population of cortical interneurons in rodents could also have dorsal origin, but this population so far was difficult to demonstrate, either because their time of genesis is very short or because this population is very small. Our experiments using parallel approaches in human and mouse brain do not support cortical origin of interneurons in E16-E17 mouse brain. It is, however, possible that we could have missed a small population of dorsally generated mouse cortical interneurons because of already mentioned low-transfection efficacy of RG in culture. In contrast to rodents, evolutionary changes in human resulted in the large brain, longer developmental period, expanded cortical surface with new cortical areas, and larger upper cortical layers II-IV (Hill and Walsh, 2005; Molnar et al., 2006; Rakic, 2009). Studies on earlier fetal and embryonic stages in human demonstrated bipolar GABAergic and CalRimmunolabeled cells both in the ventral GE and in the dorsal VZ/SVZ, suggesting dual origin of these interneurons (Rakic and Zecevic, 2003b; Zecevic et al., 2011). The neocortical SVZ increases in size and complexity in primates and animals with gyrencephalic cortex to include the outer SVZ (Smart et al., 2002; Zecevic et al., 2005; Lukaszewicz et al., 2006; Bayatti et al., 2008; Fietz et al., 2010; Hansen et al., 2010). In the human fetal brain, this zone contains several interneuronal progenitors, such as $\mathrm{Nkx} 2.1^{+}, \mathrm{Dlx}^{+}$, and CalR ${ }^{+}$cells that actively proliferate at midterm (Letinic et al., 2002; Jakovcevski et al., 2010; Zecevic et al., 2011). This is in sharp contrast to findings in rodents (de Carlos et al., 1996; Anderson et al., 1997, 1999; Tamamaki et al., 1997; Lavdas et al., 1999; Marin and Rubenstein, 2001).

\section{Late-born cortical interneurons}

The question is how different are neocortical interneurons that are born early and late during neurogenesis? Early-born interneurons are generated mainly in the GE, migrate tangentially, and end up in deep cortical layers (Jakovcevski et al., 2010; Zecevic et al., 2011). Late generated neocortical interneurons, on the other hand, are derived mainly from the outer SVZ around midterm, migrate radially, and are destined for upper cortical layers. However, some early-generated interneurons from GE can migrate first tangentially and then radially toward the cortical plate (Letinic et al., 2002; Rakic and Zecevic, 2003b). Similarly, a fraction of late-born cortical interneurons in human can tangentially migrate from the CGE to upper cortical layers in the ventral cortex or hippocampus, as has been described in rodents (Kanatani et al., 2008; Miyoshi et al., 2010).

In general, however, it seems that early and late neocortical interneurons are involved in different cortical circuitry and probably support different functions in the brain.

Evolution has led to an increased proportion and diversity of neocortical interneurons in humans, the majority of which are bipolar CalR ${ }^{+}$cells (DeFelipe, 2002; DeFelipe et al., 2006). In primates, these late-born CalR ${ }^{+}$cells are vertically oriented double-bouquet cells in upper cortical layers where they connect not only with pyramidal neurons, as would be expected, but also with other interneurons (Gabbott et al., 1997; Zaitsev et al., 2005). In rodents, $\mathrm{CalR}^{+}$cells are not a part of Nkx2.1 linage generated in the MGE (Nobrega-Preira et al., 2008; Xu et al., 2008), but instead they originate in the CGE (Fogarty et al., 2007; Miyoshi et al., 2010). In contrast, in our human material, we observed overlap between CalR ${ }^{+}$and $\mathrm{Nkx}_{2} \cdot 1^{+}$cell populations at midterm human neocortex (Jakovcevski et al., 2010), suggesting a species difference in $\mathrm{Nkx} 2.1^{+}$cell-fate determination. However, we cannot entirely exclude the possibility that CalR might be temporarily expressed in some cells at this stage of development, as has been shown for a subpopulation of calbindin ${ }^{+}$cells in the rat cortex (Alcantara et al., 1996). Pyramidal neurons from upper cortical layers (II-IV) establish corticocortical connections and are involved in higher brain functions that distinguish humans from other species (Hill and Walsh, 2005; Molnar et al., 2006; Rakic, 2009). Importantly, neocortical interneurons in the upper layers are suggested to be involved in the pathology of various psychiatric disorders, such as schizophrenia and epilepsy (Lewis et al., 2005; Levitt et al., 2006).

\section{Conclusion}

The results of this study provide evidence that GABAergic cells are generated from human but not mouse pallial progenitors. These progenitors are mainly dorsal RG cells. This, however, does not exclude other possible progenitors of neocortical interneurons in the human outer SVZ or in the GE. Indeed, the human brain is characterized by a variety of progenitors and sites for cortical interneuron generation that exceeds these of other mammals (Letinic et al., 2002; Jakovcevski et al., 2010; Zecevic et al., 2011). Additional studies are needed to establish whether RG cells are common progenitors for several cortical interneuron lineages, such as $\mathrm{Dlx}^{+}, \mathrm{Nkx}_{2} \cdot 1^{+}$, and $\mathrm{CalR}^{+}$cells. Our results demonstrate that $\mathrm{RG}$ isolated from the mouse subpallium generates cells labeled with interneuron markers, adding to an already reported role of RG as progenitors of cortical projection neurons (Malatesta et al., 2000; Miyata et al., 2001; Noctor et al., 2001; Campbell and Gotz, 2002).

Knowledge of human cortical interneuron diversity and origin is critical for understanding how the initial cortical circuitry is established. Moreover, understanding the vulnerability and the response of late-born interneurons to environmental factors would be relevant for future creation of more targeted treatments of psychiatric disorders.

\section{References}

Alcantara S, de Lecea L, Del Rio JA, Ferrer I, Soriano E (1996) Transient colocalization of parvalbumin and calbindin D28k in the postnatal cerebral cortex: evidence for a phenotypic shift in developing nonpyramidal neurons. Eur J Neurosci 8:1329-1339.

Anderson S, Mione M, Yun K, Rubenstein JL (1999) Differential origins of neocortical projection and local circuit neurons: role of Dlx genes in neocortical interneuronogenesis. Cereb Cortex 9:646-654.

Anderson SA, Eisenstat DD, Shi L, Rubenstein JL (1997) Interneuron migration from basal forebrain to neocortex: dependence on Dlx genes. Science 278:474-476.

Bayatti N, Moss JA, Sun L, Ambrose P, Ward JF, Lindsay S, Clowry GJ (2008) A molecular neuroanatomical study of the developing human neocortex from 8 to 17 postconceptional weeks revealing the early differentiation of the subplate and subventricular zone. Cereb Cortex 18:1536-1548.

Bystron I, Blakemore C, Rakic P (2008) Development of the human cerebral cortex: Boulder Committee revisited. Nat Rev Neurosci 9:110-122.

Campbell K, Gotz M (2002) Radial glia: multi-purpose cells for vertebrate brain development. Trends Neurosci 25:235-238.

de Carlos JA, Lopez-Mascaraque L, Valverde F (1996) Dynamics of cell migration from the lateral ganglionic eminence in the rat. J Neurosci 16:6146-6156

DeFelipe J (2002) Cortical interneurons: from Cajal to 2001. Prog Brain Res $136: 215-238$ 
DeFelipe J, Ballesteros-Yanez I, Inda MC, Munoz A (2006) Double-bouquet cells in the monkey and human cerebral cortex with special reference to areas 17 and 18. Prog Brain Res 154:15-32.

Fertuzinhos S, Krsnik Z, Kawasawa YI, Rasin MR, Kwan KY, Chen JG, Judas M, Hayashi M, Sestan N (2009) Selective depletion of molecularly defined cortical interneurons in human holoprosencephaly with severe striatal hypoplasia. Cereb Cortex 19:2196-2207.

Fietz SA, Kelava I, Vogt J, Wilsch-Brauninger M, Stenzel D, Fish JL, Corbeil D, Riehn A, Distler W, Nitsch R, Huttner WB (2010) OSVZ progenitors of human and ferret neocortex are epithelial-like and expand by integrin signaling. Nat Neurosci 13:690-699.

Fogarty M, Grist M, Gelman D, Marin O, Pachnis V, Kessaris N (2007) Spatial genetic patterning of the embryonic neuroepithelium generates GABAergic interneuron diversity in the adult cortex. J Neurosci 41: 10935-10946.

Gabbott PL, Jays PR, Bacon SJ (1997) Calretinin neurons in human medial prefrontal cortex (areas 24a,b,c, 32', and 25). J Comp Neurol 381: $389-410$.

Gotz M, Bolz J (1994) Differentiation of transmitter phenotypes in rat cerebral cortex. Eur J Neurosci 6:18-32.

Gulacsi A, Lillien L (2003) Sonic hedgehog and bone morphogenetic protein regulate interneuron development from dorsal telencephalic progenitors in vitro. J Neurosci 23:9862-9872.

Hansen DV, Lui JH, Parker PR, Kriegstein AR (2010) Neurogenic radial glia in the outer subventricular zone of human neocortex. Nature 464: $554-561$.

He W, Ingraham C, Rising L, Goderie S, Temple S (2001) Multipotent stem cells from the mouse basal forebrain contribute GABAergic neurons and oligodendrocytes to the cerebral cortex during embryogenesis. J Neurosci 21:8854-8862.

Hill RS, Walsh CA (2005) Molecular insights into human brain evolution. Nature 437:64-67.

Howard BM, Chen Y, Zecevic N (2006) Cortical progenitor cells in the developing human telencephalon. Glia 53:57-66.

Howard BM, Zhicheng M, Filipovic R, Moore AR, Antic SD, Zecevic N (2008) Radial glia cells in the developing human brain. Neuroscientist 14:459-473.

Inta D, Alfonso J, von Engelhardt J, Kreuzberg MM, Meyer AH, van Hooft JA, Monyer H (2008) Neurogenesis and widespread forebrain migration of distinct GABAergic neurons from the postnatal subventricular zone. Proc Natl Acad Sci U S A 105:20994-20999.

Jakovcevski I, Zecevic N (2005) Olig transcription factors are expressed in oligodendrocyte and neuronal cells in human fetal CNS. J Neurosci 25:10064-10073.

Jakovcevski I, Mayer N, Zecevic N (2010) Multiple origins of human neocortical interneurons are supported by distinct expression of transcription factors. Cereb Cortex. Advance online publication. Retrieved December 15, 2010. doi:10.1093/cercor/bhq245.

Kanatani S, Yozu M, Tabata H, Nakajima K (2008) COUP-TFII is preferentially expressed in the caudal ganglionic eminence and is involved in the caudal migratory stream. J Neurosci 28:13582-13591.

Kessaris N, Fogarty M, Iannarelli P, Grist M, Wegner M, Richardson WD (2006) Competing waves of oligodendrocytes in the forebrain and postnatal elimination of an embryonic lineage. Nat Neurosci 9:173-179.

Kohwi M, Petryniak MA, Long JE, Ekker M, Obata K, Yanagawa Y, Rubenstein JL, Alvarez-Buylla A (2007) A subpopulation of olfactory bulb GABAergic interneurons is derived from Emx1- and Dlx5/6-expressing progenitors. J Neurosci 27:6878-6891.

Lavdas AA, Grigoriou M, Pachnis V, Parnavelas JG (1999) The medial ganglionic eminence gives rise to a population of early neurons in the developing cerebral cortex. J Neurosci 19:7881-7888.

Letinic K, Zoncu R, Rakic P (2002) Origin of GABAergic neurons in the human neocortex. Nature 417:645-649.

Levitt P, Ebert P, Mirnics K, Nimgaonkar VL, Lewis DA (2006) Making the case for a candidate vulnerability gene in schizophrenia: convergent evidence for regulator of G-protein signaling 4 (RGS4). Biol Psychiatry 60:534-537.

Lewis DA, Hashimoto T, Volk DW (2005) Cortical inhibitory neurons and schizophrenia. Nat Rev Neurosci 6:312-324.

Lukaszewicz A, Cortay V, Giroud P, Berland M, Smart I, Kennedy H, Dehay C (2006) The concerted modulation of proliferation and migration contributes to the specification of the cytoarchitecture and dimensions of cortical areas. Cereb Cortex 16 [Suppl 1]:i26-i34.
Malatesta P, Hartfuss E, Gotz M (2000) Isolation of radial glial cells by fluorescent-activated cell sorting reveals a neuronal lineage. Development 127:5253-5263.

Marin O, Rubenstein JL (2001) A long, remarkable journey: tangential migration in the telencephalon. Nat Rev Neurosci 2:780-790.

Marshall CA, Goldman JE (2002) Subpallial dlx2-expressing cells give rise to astrocytes and oligodendrocytes in the cerebral cortex and white matter. J Neurosci 22:9821-9830.

Miyata T, Kawaguchi A, Okano H, Ogawa M (2001) Asymmetric inheritance of radial glial fibers by cortical neurons. Neuron 31:727-741.

Miyoshi G, Hjerling-Leffler J, Karayannis T, Sousa VH, Butt SJ, Battiste J, Johnson JE, Machold RP, Fishell G (2010) Genetic fate mapping reveals that the caudal ganglionic eminence produces a large and diverse population of superficial cortical interneurons. J Neurosci 30:1582-1594.

Mo Z, Zecevic N (2008) Is Pax6 critical for neurogenesis in the human fetal brain? Cereb Cortex 18:1455-1465.

Mo Z, Zecevic N (2009) Human fetal radial glia cells generate oligodendrocytes in vitro. Glia 57:490-498.

Mo Z, Moore AR, Filipovic R, Ogawa Y, Kazuhiro I, Antic SD, Zecevic N (2007) Human cortical neurons originate from radial glia and neuronrestricted progenitors. J Neurosci 27:4132-4145.

Molnar Z, Metin C, Stoykova A, Tarabykin V, Price DJ, Francis F, Meyer G, Dehay C, Kennedy H (2006) Comparative aspects of cerebral cortical development. Eur J Neurosci 23:921-934.

Nóbrega-Pereira S, Kessaris N, Du T, Kimura S, Anderson SA, Marín O (2008) Postmitotic Nkx2-1 controls the migration of telencephalic interneurons by direct repression of guidance receptors. Neuron 59:733-745.

Noctor SC, Flint AC, Weissman TA, Dammerman RS, Kriegstein AR (2001) Neurons derived from radial glial cells establish radial units in neocortex. Nature 409:714-720.

Pappas IS, Parnavelas JG (1998) Basic fibroblast growth factor promotes the generation and differentiation of calretinin neurons in the rat cerebral cortex in vitro. Eur J Neurosci 10:1436-1445.

Petanjek Z, Kostovic I, Esclapez M (2009a) Primate-specific origins and migration of cortical GABAergic neurons. Front Neuroanat 3:26.

Petanjek Z, Berger B, Esclapez M (2009b) Origins of cortical GABAergic neurons in the cynomolgus monkey. Cereb Cortex 2:249-262.

Rakic P (2009) Evolution of the neocortex: a perspective from developmental biology. Nat Rev Neurosci 10:724-735.

Rakic S, Zecevic N (2003a) Early oligodendrocyte progenitor cells in the human fetal telencephalon. Glia 41:117-127.

Rakic S, Zecevic N (2003b) Emerging complexity of layer I in human cerebral cortex. Cereb Cortex 13:1072-1083.

Smart IH, Dehay C, Giroud P, Berland M, Kennedy H (2002) Unique morphological features of the proliferative zones and postmitotic compartments of the neural epithelium giving rise to striate and extrastriate cortex in the monkey. Cereb Cortex 12:37-53.

Sussel L, Marin O, Kimura S. Rubenstein JL (1999) Loss of Nkx2.1 homeobox gene function results in a ventral to dorsal molecular respecification within the basal telencephalon: evidence for a transformation of the pallidum into the striatum. Development 126:3359-3370.

Tamamaki N, Fujimori KE, Takauji R (1997) Origin and route of tangentially migrating neurons in the developing neocortical intermediate zone. J Neurosci 17:8313-8323.

Xu Q, Wonders CP, Anderson SA (2005) Sonic hedgehog maintains the identity of cortical interneuron progenitors in the ventral telencephalon. Development 132:4987-4998.

Xu Q, Tam M, Anderson SA (2008) Fate mapping Nkx2.1-lineage cells in the mouse telencephalon. J Comp Neurol 506:16-29.

Yu X, Jakovcevski I, Mo Z, Zecevic N (2009) Cortical origin of calretininexpressing neurons in the human fetal forebrain. Soc Neurosci Abstr 39:807.12/A12.

Zaitsev AV, Gonzalez-Burgos G, Povysheva NV, Kroner S, Lewis DA, Krimer LS (2005) Localization of calcium-binding proteins in physiologically and morphologically characterized interneurons of monkey dorsolateral prefrontal cortex. Cereb Cortex 15:1178-1186.

Zecevic N, Chen Y, Filipovic R (2005) Contributions of cortical subventricular zone to the development of the human cerebral cortex. J Comp Neurol 491:109-122.

Zecevic N, Hu F, Jakovcevski I (2011) Cortical interneurons in the developing human neocortex. J Neurobiol 71:18-33. 